\title{
Simulation of knee implants made of Ti6Al4V material during walking
}

\author{
Djoko Kustono ${ }^{1 *}$, Retno Wulandari ${ }^{1}$, Andoko ${ }^{1}$, Poppy Puspitasari $^{1}$, Galih Adhi Kurniawan ${ }^{1}$, \\ and Agus Dwi Putra ${ }^{1}$ \\ ${ }^{1}$ Department of Mechanical Engineering, Faculty of Engineering Universitas Negeri Malang, 65145 \\ Malang, Indonesia
}

\begin{abstract}
Bone is the connective tissue in the human body which consists of cells, fibers, and extracellular matrix. The bone matrix is the hardest part located in the outer layer of the bone, which is caused by the deposition of minerals in the matrix, so that the bone undergoes classification. The bone functions as a hard, rigid body frame, and provides a place or space for attachment of muscles and organs found in the human body. The simulation results using FEM showed that knee implants made with Ti6Al4V material had a total deformation of $0.15 \mathrm{~mm}$, maximum principal stress of $17.012 \mathrm{MPa}$, and a maximum shear stress of $15.841 \mathrm{MPa}$. The analysis was performed using a variation of time 0 to 1.01 seconds.
\end{abstract}

\section{Introduction}

The operation of knee bone implants in the biomedical world has a high success rate. In America more than 400,000 times per year performing human bone replacement surgery (Lowry et al, 2010), even in 2030, joint repair surgery in the United States will be accelerated by $673 \%$, which is to $3,480,000$ cases [1].

Aseptic studies, osteolysis, and most common infections in total knee arthroplasty (TKA). This study examines the role and features in reducing easing, and also explores its sensitivity. From implants to surgical instruments due to oscillations [2].

Titanium can also be used in medicine, including in bone pin titanium surgery, or implants. This can be done, because titanium cannot reflect directly with the network (Stwertka, 2002). Ti6Al4V is one that has been widely used in biomedicine, especially as bone implants [3]. The element method used to analyze the deformation, shear units and principle stresses of bone implants with Ti6Al4V material. The software used is ANSYS 18.1.

\footnotetext{
* Corresponding author: djoko.kustono.ft@um.ac.id
} 


\section{Literature review}

\subsection{Implant}

Throughout the 20th century, continuous innovations in material science led to a dramatic improvement in outcomes. Among those innovations were the advent of titanium and cobalt chrome as biocompatible metals for the femur and tibial base, the introduction of polymethyl methacrylate as a biocompatible cement for fixing implants to host bones, and ultrahigh-molecular-weight polyethylene as a highly durable articulating surface. These advances in material science enabled clinicians and engineers to develop new styles of increasingly successful knee replacement [4].

Bone plate component is one of the medical devices that are made to replace the structure and function of a biological part. In the bone plate component market has a varied price depending on the material, bone plate material characterization must be carried out in order to determine the composition of chemicals, metallography, hardness and corrosion testing [5]. Implant material that is often used in orthopedics is metal. The principle of using metal biomaterials as raw material for orthopedic implants is based on the characteristics of biomechanical compatibility, biochemistry and biological compatibility that are quite good for the body. Some metal biomaterials that are often used as implant material are Ti Alloy [6]. The implant design in total knee arthroplasty (TKA) is crucial for the functional restoration of the knee and associated directly with the clinical outcome. Modular implant systems are used conventionally with a limited number of size gradations so that the Surgeon has to choose a best compromise. Thereby, for example implants can lead to functional limitations, soft tissue irritations, bleeding, increased pressure and pain and, thus, decrease durability and patient satisfaction. standard knee designs cover Korean female femora dimensions only poorly, with negative clinical outcome. Therefore, detailed knowledge about the characteristics of individual morphological features and its consideration is essential for improved endoprosthetic care [7].

\subsection{Titanium}

Titanium alloy is widely used in medical devices (e.g. orthopaedic and dental implants) due to its excellent properties including low Young's modulus, chemical stability, low thermal conductivity and biocompatibility. Ideally, an implant should meet the following criteria: biocompatibility, anti-infective efficiency, long-lasting anti-infective efficiency, good mechanical properties and antibacterial coating stability [8].

Titanium is well-known for being used successfully as an implant material, and the success is credited to its excellent biocompatibility as a result of the formation of stable oxide layers on its surface [8]. Titanium is, in fact, the metal of choice in medicine (e.g. surgical instruments, orthopaedic pins and implants). The characteristic of not reacting directly with tissue makes it a great benefit in the medical field [9]. 


\section{Processing and Method}

\subsection{Implant design}

Figure 1 shows the dimensions of the knee implant made using Autodesk Inventor 2014.

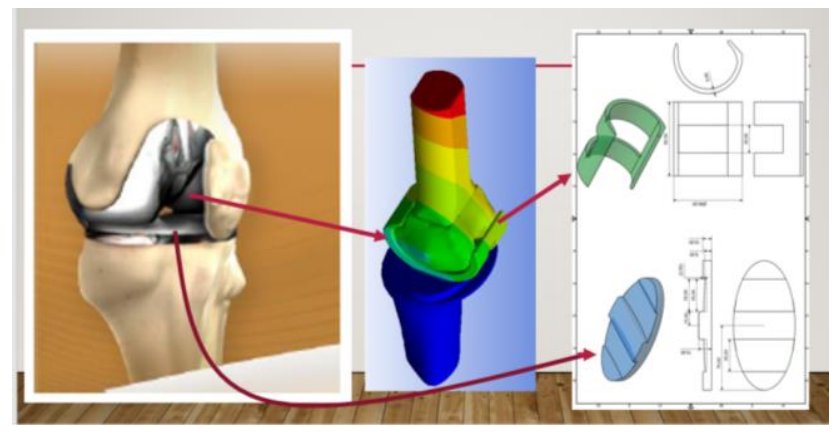

Fig. 1. Design of the Ti6A14V implant.

\subsection{ANSYS simulation}

In this study using time and load variations where loading starts from 0 to 1.01 seconds with multiples of 0.1 seconds. The analysis using FEM method with ANSYS Workbench 18.1 was carried out to investigate the maximum principal stress, maximum shear stress and total deformation of knee implants. The meshing of bone implants resulted in 167978 nodes and 96628 elements which were then analysed for damage.

\section{Result and Discussion}

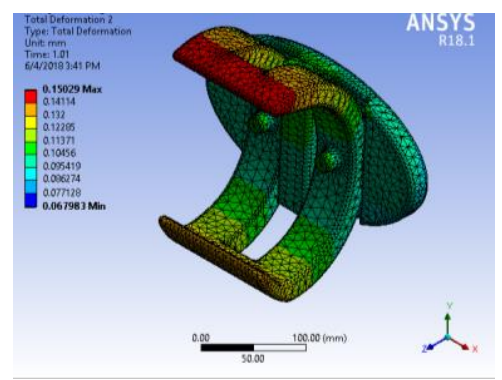

(a)

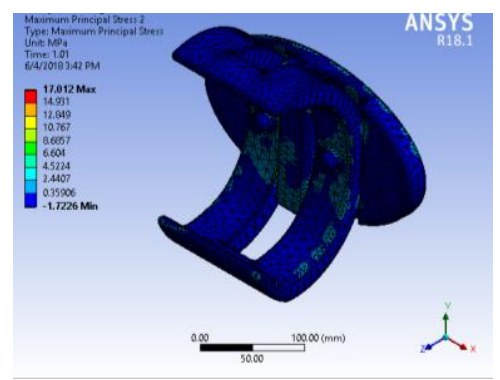

(b)

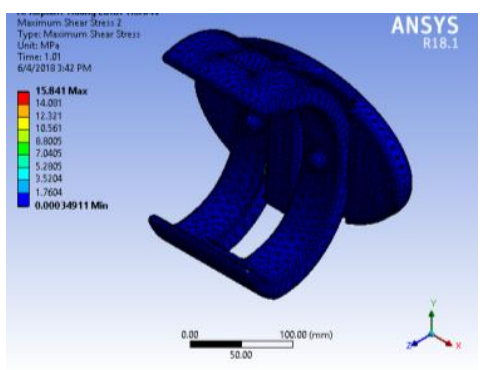

(c)

Fig. 2. Analysis results of deformation, maximum principal stress and maximum shear stress. 
The knee implant made of Ti6Al4V subjected to a force of $2703.1 \mathrm{~N}$ had a total deformation of $0.150 \mathrm{~mm}$ (see Figure 2a), maximum principal stress of $17.012 \mathrm{MPa}$ (see Figure 2b), and maximum shear stress of $15.841 \mathrm{MPa}$ (see Figure 2c).

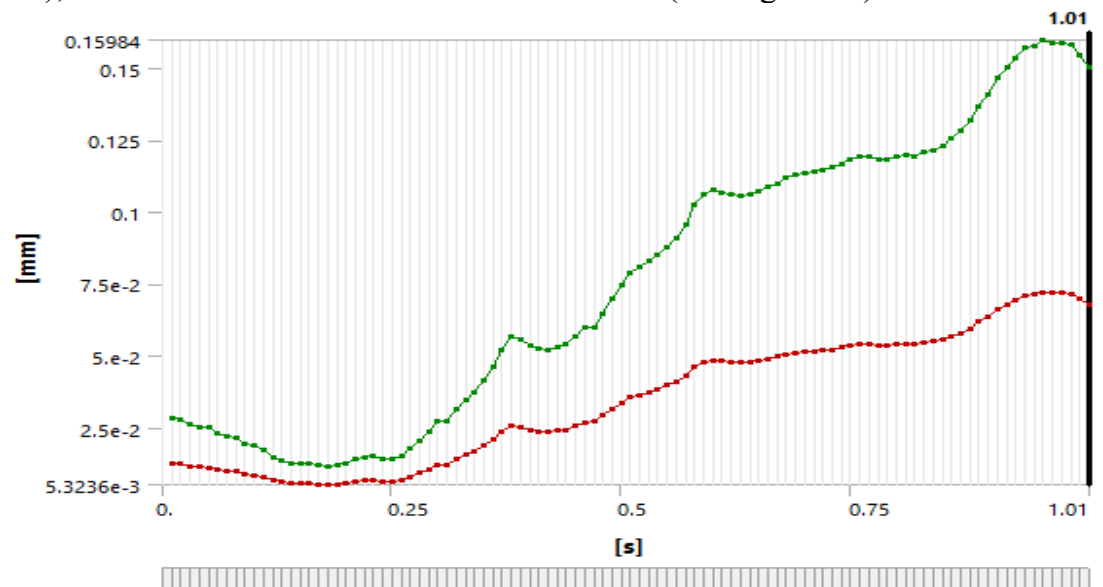

Fig. 3. Graph of total deformation.

Notes: ........... : : maximum deformation

$$
\text { :............ : minimum deformation }
$$

Figure 3 shows the total deformation of the knee implants at 0 seconds to 1.01 seconds under a different load for a different period of time.

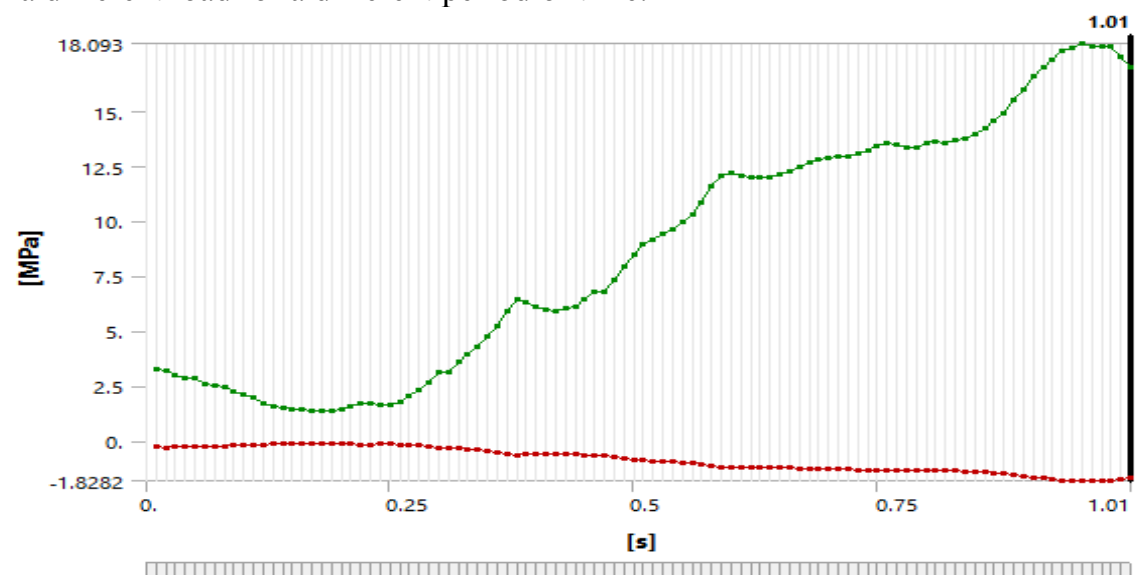

Fig. 4. Graph of maximum principal stress.

Notes: ........... : : maximum principal stress

:............ : minimum principal stress

Figure 4 shows the maximum principal stress of the knee implants at 0 seconds to 1.01 seconds under a different load for a different period of time. 


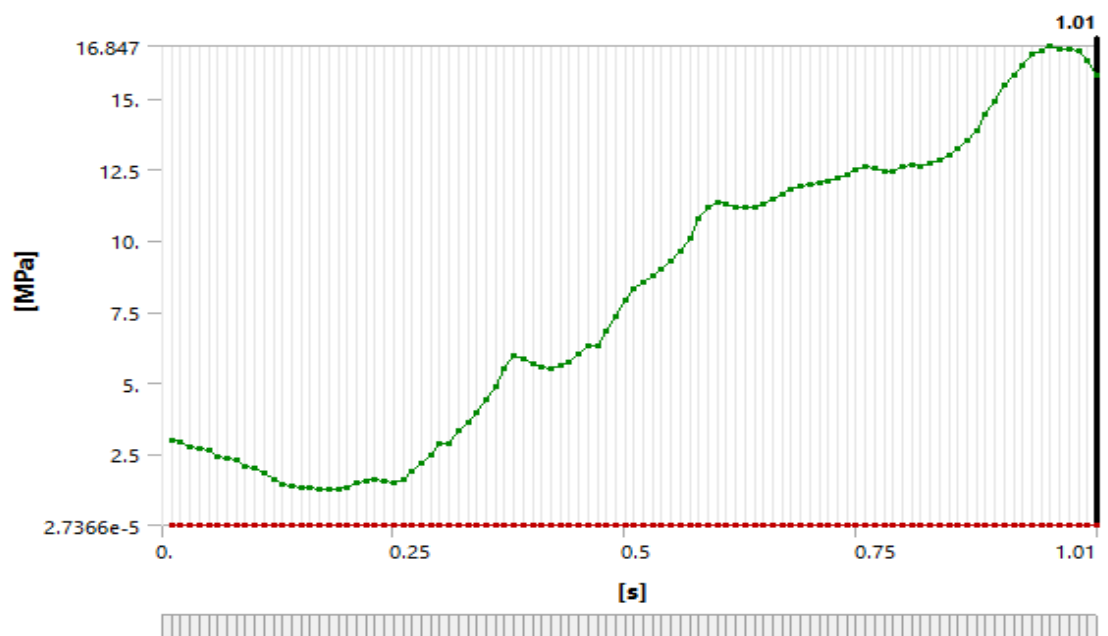

Fig. 5. Graph of maximum shear stress.

Notes: ............ : maximum shear stress

............ : minimum shear stress

Figure 5 shows the maximum shear stress of the knee implants at 0 seconds to 1.01 seconds under a different load for a different period of time.

\section{Conclusion}

The results of the analysis using the finite element method showed that the knee implant made of Ti6Al4V had a total deformation of $0.15 \mathrm{~mm}$, maximum principal stress of 17.012 $\mathrm{MPa}$, and maximum shear stress of $15.841 \mathrm{MPa}$. The analysis was carried out during the walking activity for 0 seconds to 1.01 seconds under different forces.

The authors acknowledge to State University of Malang for Hibah Penelitian PNBP UM 2018 with contract number 2.3.175/UN32.14/LT/2018.

\section{References}

1. J. Slover and J. D. Zuckerman, "Increasing Use of Total Knee Replacement and Revision Surgery," JAMA, 308, 1266 (2012)

2. N. Conlisk, C. R. Howie, and P. Pankaj, "Computational modelling of motion at the bone-implant interface after total knee arthroplasty: The role of implant design and surgical fit," Knee, (2017)

3. C. N. Elias, J. H. C. Lima, R. Valiev, and M. a Meyers, "Biomedical Applications of Titanium and its Alloys," J. Miner. Met. Mater. Soc., 46-49 (2008)

4. C. Clary and L. Maletsky, Mechanical testing of knee implants. Elsevier Ltd., (2017)

5. C. Sutowo, M. Ikhsan, J. T. Mesin, U. Muhammadiyah, I. Kartika, "CHARACTERISTICS OF MATERIALS BIOCOMPETIBLE ". 1-5, 2014.

6. L. Belakang, "BAB I," 1-3, 2015.

7. M. Asseln, C. Hänisch, F. Schick, and K. Radermacher, "The Knee Gender differences in knee morphology and the prospects for implant design in total knee replacement," Knee, 25 (4), 545-558 (2018)

8. R. A. Martínez, "Fracture surfaces and the associated failure mechanisms in ductile 
iron with different matrices and load bearing," Eng. Fract. Mech., 77 (14), 2749-2762 (2010)

9. A. Stwertka, A Guide to the Elements. Ner York: Oxford Press, 2002. 